\title{
ENTRE MODOS DE VER E MODOS DE LER, O DIZER
}

RESUMO: Este texto propõe compreender como se confrontam a natureza icônica e verbal que permeiam duas linguagens, a visual e a verbal, com a finalidade de pensar os sentidos da leitura literária para crianças e refletir sobre formação de professores. A escrita é vista como uma estrutura mista, apoiada em dois registros, verbal e gráfico, e a imagem, entendida como um conjunto de figura e suporte. As abordagens sobre a relação entre o icônico e o verbal apoiam-se em estudos sobre literatura e artes plásticas dando margem à constituição de dois grandes eixos de análise: o paradoxo e o paralelo. O livro de literatura infantil oferece exemplos para a presente discussão, pois se comporta de forma dinâmica e maleável frente às diferentes mídias.

Palavras-chave: Literatura Infantil; O Icônico; O Verbal.

\section{BETWEEN SEEING AND READING - THE SAYING}

ABSTRACT: In this article, we compare the iconic and verbal natures that permeate the visual and verbal languages in order to analyze the meanings of literary reading for children and reflect on teacher education. Writing is perceived as a mixed structure supported by two registers - verbal and graphic, while image is considered as a picture and support set. The approaches concerning the relation between the iconic and verbal aspects are supported by studies on the literature and the fine arts, which provide ground for the building of two major axes of analysis: the paradox and the parallel. Children literature books provide examples for this discussion, since they present a dynamic and flexible behavior in face of the different types of media.

Keywords: Children Literature; Iconic Aspect; Verbal Aspect.

\footnotetext{
*Doutora em Educação pela Universidade Federal Fluminense (UFF); Pesquisadora do Centro de Alfabetização, Leitura e Escrita (CEALE) e Professora Adjunta da Universidade Federal de Minas Gerais (UFMG). E-mail: celiab@terra.com.br
} 


\section{INTRODUCุÃO}

Este trabalho ${ }^{1}$ (BELMIRO, 2008) se propõe a compreender como se confrontam a natureza icônica e verbal que permeiam duas linguagens, a visual e a verbal, com a finalidade de pensar as diferentes leituras e os sentidos da leitura literária. Pretende ainda refletir sobre a importância da formação dos professores nessa área e as consequentes contribuições a seu trabalho em sala de aula.

As diversas possibilidades de elaboração de narrativas mostram, por exemplo, que atualmente o "livro brinquedo" frequenta as estantes de livrarias, de bibliotecas públicas e escolares de forma a cumprir um papel que, por vezes, ultrapassa a ideia de lazer/brincadeira. Ver alguma coisa, brincar e criar histórias a partir dela é o que se oferece a crianças que não dominam o sistema de escrita alfabética mas que podem produzir sentidos utilizando estruturas textuais da língua que já dominam. Recuperar a instância de relativa autonomia e dependência entre essas linguagens (visual e verbal escrita) aponta, nos livros de literatura infantil, diálogos e tensões do jogo interativo próprio de quem se constitui pela linguagem. O eixo que norteia as determinações teóricas e os níveis de relação entre o icônico e o verbal neste trabalho se constitui a partir dos estudos sobre literatura e artes plásticas, destacando um arco de possibilidades para a construção de reiterações, especificidades, alternâncias no uso dessas linguagens.

A posição de Christin (1995) nos ajuda a compreender, por exemplo, que as práticas de ver e comentar (portanto, produzir leitura) sequências mitográficas nas sociedades orais não indicam, necessariamente, que esses enunciados sirvam de tradução das imagens em palavras por não haver outro modo de compreendê-las. A autora lembra que essa prática se encontra menos nas sociedades em que a fala e a imagem se completam segundo modalidades, algumas variáveis, mas sem jamais se redobrarem de forma redundante. Por outro lado, a tese da filiação verbal da escrita ocultou por muito tempo as funções gráficas do sistema. Procurar uma origem da escrita na imagem, privilegiando aí as imagens, é não compreender a imagem no que ela tem de específico, de característico do seu sistema, e projetar sobre ela um modelo de explicação que se torna, uma vez mais, linguageiro; é submeter as imagens a uma explicação de orientação verbal, pois o espaço físico se torna invisível e as figuras, como representações do 
real, se organizam em sistema como uma sorte de utopia paraverbal. Deve-se entender a escrita como uma linguagem de dupla entrada: verbal e gráfica, um estudo semiótico ampliado, tendo cada uma as suas especificidades. A existência do grafismo como constitutivo da escrita, ao lado do fonetismo, permite o investimento na semantização das figuras, com valor de símbolo. Por isso, a autora propõe recuperar a importância da categoria superfície, aparentemente um espaço cego, e amplia a concepção de escrita por dupla origem. Christin (1995, p. 11):

O que caracteriza essencialmente a estrutura da escrita é sua capacidade de ser mista: porque seu sistema se apóia em dois registros ao mesmo tempo, o verbal e o grafismo, mas também porque esses registros são inteiramente heterogêneos um ao outro ${ }^{2}$.

Podemos observar que essa característica gráfica é vista não somente na poesia, nas artes em geral. A banalidade da presença gráfica da linguagem nos lugares sociais, nas formas cotidianas do dizer ultrapassa a ruptura da linearidade fônica e da sequência silogística aristotélica (sujeito, combinação, predicado) para encarnar-se nas manifestações de liberdade estética que incluem o verbal e o visual, na montagem cinematográfica que solicita do espectador velocidade para exploração e compreensão dos cortes e para criação de hipóteses no exercício pleno de reconstrução de sentidos.

Por outro lado, a perspectiva antropológica de Mignolo (1994) sobre a escrita pictográfica dos povos ameríndios se aproxima das questões acima levantadas, pois contribui para relativizar a forte presença da lógica ocidental no modo de organização e explicação do mundo, uma vez que aquela obedecia a parâmetros de outra ordem. A noção de tempo é dada por outros mecanismos de linguagem que não correspondem à linearidade da escrita alfabética e que, no entanto, conseguem produzir uma memória. Isso desnorteou a atenção dos espanhóis para o modo como verdadeiramente se realizavam não só uma sofisticada prática de escrita e comportamento verbal quanto conceitualizações complexas dessas práticas e comportamentos. Assim, ler esses símbolos adquire um significado que não vai ao encontro dos procedimentos de leitura alfabética.

Outra preocupação de Christin é a recuperação da cegueira do espaço vazio, uma presença que hierarquiza formas variadas a ponto de tornar esse vazio um outro. Contrapondo épocas em que o conhecimento 
humano propõe novas epistemes, a pesquisadora analisa o invisível que se coloca pela presença do espaço representado na imagem da pintura renascentista como expressão de uma metafísica. Além disso, o trompe l'oeil, a ilusão de óptica que a perspectiva renascentista provoca é, para ela, uma perversão das figuras, embora uma definição científica do fenômeno refira-se a "um conflito perceptivo". De qualquer forma, há uma preocupação em mostrar que o estudo da imagem inclui não só a figura, pois não revelaria a importância que o intervalo empresta na constituição de uma escrita (1995, p. 20): “É esse pensamento do 'fundo', esse pensamento do vazio não ponto neutro, mas capaz de engendrar a seu turno uma 'forma' inédita, própria ao homem, e que se inscreve como tal no mundo, que inventou a escrita". Portanto, o intervalo que separa as figuras participa da constituição da sua dinâmica semântica, sua sintaxe. O que determina o valor semântico do vazio pictural, isto é, dos espaços entre as figuras é que, mesmo que as figuras sejam inteiramente polissêmicas, ele mesmo é polissintático, permitindo variadas formas de relação. Assim, ao lado de uma polissemia das figuras, tem-se uma polissintaxe do espaço, constituindo-se, consequentemente, uma semântica espacial.

Acredito que esse modo de completude entre as imagens e a oralidade pode nos levar a pensar em duas hipóteses: uma, que não havia uma sobredeterminação do oral sobre a imagem, mas uma retórica própria da oralidade e uma organização própria de assentamento espacial das figuras; outra, que a carga semântica das imagens e a retórica do texto oral fazem a história dos povos ameríndios. Futuramente ver-se-á que a ideologia educacional da correção fará mesclarem-se a prática oral e a prática escrita, ambas baseadas na gramática e na retórica.

O livro de literatura infantil oferece exemplos pertinentes para a presente discussão, uma vez que tem se comportado de forma dinâmica e maleável frente às diferentes mídias, cujas tecnologias dão feições inusitadas às relações entre imagens e textos verbais, sejam orais ou escritos. Com o intuito de dar mais visibilidade às obras analisadas e iluminar as discussões teóricas que se seguem, optamos por apresentar previamente a análise do corpus.

\section{PERSPECTIVAS DE ANÁLISE}

Ainda que correndo o risco de parcialidade do estudo, cabe apresentar duas grandes perspectivas de análise das relações entre o legível 
e o visível apoiadas em Arbex (2006), de forma a acrescentar contribuições às investigações contemporâneas no campo e organizar algumas propostas de classificação. São elas: a perspectiva da natureza das obras e a perspectiva pragmática.

\section{PERSPECTIVA DA NATUREZA DAS OBRAS}

A pesquisa de Arbex (2006) indica a natureza das obras como um dos critérios de base, proposto por Monclair, apontando três categorias de obras: $1^{\text {a }}$ - a das "criadas em fusão artística" (mistura de vários códigos artísticos numa mesma obra, como a ópera, os romances com desenhos do autor etc.); $2^{\text {a }}$ - a das que "criam uma fusão" e as "adaptações" (a partir de elementos parciais pré-existentes cria-se uma nova obra, que realiza ou não a fusão das artes); $3^{\mathrm{a}}$ - as que incluem citações. Além disso, essas categorias apresentam quatro principais eixos críticos: a relação com o autor, a relação com o contexto de produção, a relação com o contexto de recepção (esses três questionando a obra do ponto de vista pragmático) e a relação da obra com as artes (a relação da mudança de código com as outras artes é o eixo da estética comparada, que será discutida posteriormente). Há uma tendência para compreender como essas formas artísticas marcam a existência umas das outras, ou seja, se pode haver prevalência de uma delas e, se houver, como se dá essa tensão. A crítica vem apontando quatro pontos de interação: a - duas formas artísticas para uma mesma interrogação, "[...] escrever e pintar, ou fazer da pintura o objeto do discurso literário, são abordagens inscritas numa pesquisa formal ou filosófica”. (p. 42); $\mathrm{b}$ - a pintura como fonte de inspiração para o escritor (o autor constrói uma estética própria a partir da observação da pintura); c - a pintura como motivo do texto (o autor se serve do quadro como motivo de descrição); $\mathrm{d}$ - a pintura inspirada pela literatura.

Ora, se observarmos os materiais da área de linguagem com que os alunos de todos os anos da escola básica lidam é fácil perceber que esses pontos são fortemente marcados por critérios de hierarquização e valor frente às relações estabelecidas entre o plástico, o verbal e o gráfico. Justifica-se aqui o conceito bakhtiniano de signo ideológico que constitui as relações entre os sujeitos e, pode-se acrescentar, entre as diferentes formas 
de expressão elas mesmas. Basta atentar para as interpretações de texto verbal e imagens, para verificar que um modo define os outros modos de compreender a realidade. Interrogam-se, muitas vezes, a linguagem verbal, as pinturas ou os grafismos nos livros didáticos de Português como se fossem da mesma natureza, pois não são marcadas as formas próprias de se constituírem. Muito menos marcada a natureza da relação que essas formas estabelecem, como se bastasse aproximação física no suporte para constituírem-se como obras dialogantes. Considerando que a linguagem constitui o sujeito, pode-se reafirmar que a natureza constitutiva dessas outras linguagens também institue os sujeitos, contemporâneos e híbridos, detentores de uma diversidade de modos de expressão que precisam ser reconhecidos pelo sistema escolar e devolvidos aos sujeitos-alunos em forma de atividades.

\section{PERSPECTIVA PRAGMÁTICA}

Outro caminho de análise parte da hipótese de que os tipos de relação entre imagem e texto dependem de sua situação de comunicação e não da natureza intrínseca do texto verbal e da imagem. Arbex (2006, p. 43-44) sinaliza as investigações de Hoek, a partir do estudo de textos que se inspiraram em obras de arte e que têm um referente pictural. Sua proposta de classificação indica uma dada situação de comunicação (de produção ou de recepção), a relação imagem-texto proposta (se primazia da imagem, se do texto, se simultaneidade, se correferência) e a tipologia das obras (multimedial, transmedial, discurso misto, discurso sincrético).

É possível aproveitar alguns elementos desse quadro classificatório como base para um mapeamento mais amplo das formas em que se apresentam textos e imagens. Por outro lado, a tipologia das obras merece atenção, pois sua caracterização implica a presença de ambos, ou a anterioridade de um sobre o outro, isto é, se imagem ou texto serve de base para a realização do outro. Essa classificação vai permitir um avanço de propostas teóricometodológicas, considerando texto e imagem como autônomos, tomando corpo a partir de injunções históricas, sejam individuais ou coletivas. Vários autores têm se preocupado em tratar dessa relação, construindo categorias 
com base no textual ou no pictural, mas sempre abarcando os dois elementos de referência.

\section{SEMÂNTICA DAS IMAGENS/VISUALIDADE DO DISCURSO VERBAL - A ANÁLISE DO MATERIAL}

Essa seção apresenta um estudo exploratório de livros de literatura infantil em que as categorias do visível e do legível atravessam as relações entre imagem e texto verbal. A escolha do material aqui apresentado estabelece características exemplares da discussão a ser desenvolvida. São publicações contemporâneas que indicam caminhos percorridos por autores e ilustradores para que essas duas dimensões de expressão possam ser ou não permeadas uma pela outra. Relevante observar, no material apresentado, ainda, os imbricamentos entre as duas linguagens, quando as funções de autor e de ilustrador são realizadas pela mesma pessoa, pois sua liberdade na composição do espaço/tempo expressa-se de forma evidente. Outro aspecto a destacar é que a necessidade humana de contar histórias é uma característica prosaica que pode ser explicitada por diferentes linguagens.

Em Rodolfo, o carneiro, o autor e ilustrador de língua inglesa Rob Scotton desenvolve um projeto gráfico-editorial que acolhe o diálogo entre palavra e imagem, um buscando o outro para se completarem e complementarem sentidos possíveis: o texto acompanha o desenho, em cima ou embaixo dele, fora ou dentro do quadro, sempre adequando sua presença às intenções gráficas da paginação. Um bom exemplo é o das p. 13/14 (Figura 1), em que o texto diz: "Não importava o quanto tentasse, Rodolfo não conseguia cair no sono" (SCOT'TON, 2006).

O caminho em labirinto do texto, que acompanha o movimento em novelo do gorro de dormir, dá visibilidade ao leitor da dificuldade do carneiro em relaxar. Ainda que a decodificação das palavras use os procedimentos canônicos do sistema de escrita alfabética, a leitura não o faz, adquirindo sentidos renovados pela forma e pela proposta de uso do suporte, que deve ser girado para acompanhar a direção de leitura apresentada. Como cantoneiras, carneirinhos nas pontas da folha do papel sugerem posições ensaiadas pelo bichinho, na tentativa de se acomodar. Esse jogo verbovisual permite que cada linguagem expresse alguma coisa, acrescentando-se mutuamente. Na p. 11 (Figura 2), por 
Figura 1

Rodolfo o Carneiro, p. 13.

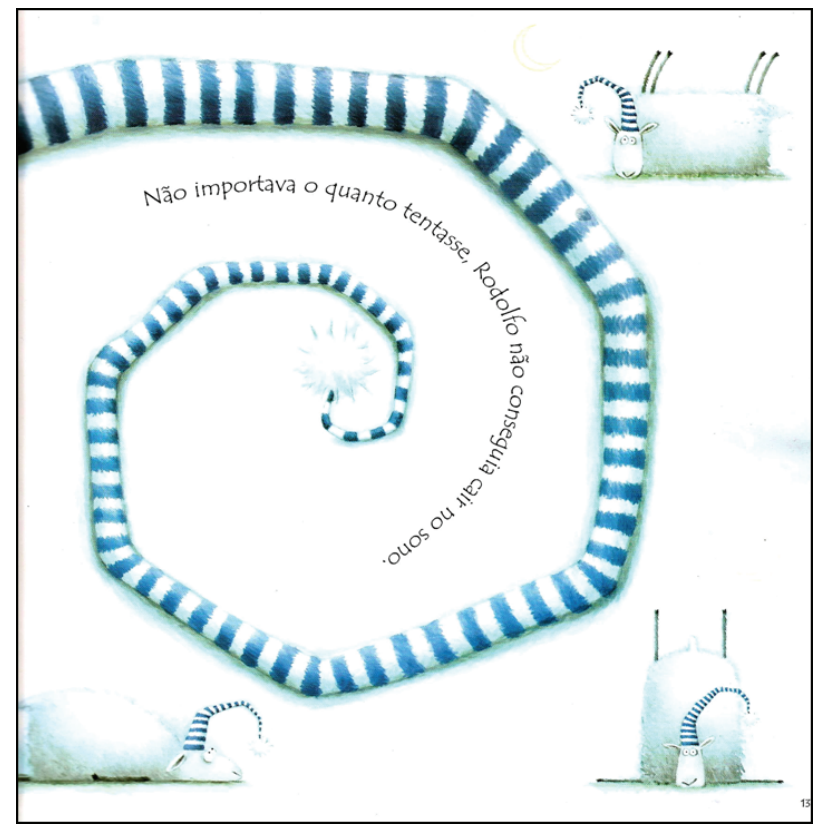

Fonte: Scotton (2006).

exemplo, a noite é apresentada por um desenho pequeno dos carneirinhos, no centro da folha, fazendo com que todo o branco em volta participe ativamente da história, como moldura que ajuda o silêncio (em branco) a emudecer a noite: tudo quieto, como um quadro. Essa condensação de elementos para repercutir uma ideia concretiza-se, nesse discurso, como uma proposta poética. O texto acompanha a inclinação da curva da moldura para compor a leitura da página, que não é do texto ou do desenho: são os dois, além do branco do papel, da inclinação da moldura e do texto. Nesse caso, o branco não é o vazio, mas um espaço de plasticidade que participa significativamente dos sentidos da página.

Todo esse contexto dá chance de a palavra seguinte, que quebra esse conjunto, contrastar. Na ponta da direita embaixo, isto é, no último lugar de escrita da folha, pronto para virar a página, a palavra exceto suspende a tranquilidade e a harmonia do conjunto do quadro para preparar o conflito: “exceto...”: Rodolfo, o carneiro, não consegue dormir.

Outra obra significativa para a presente discussão é $O$ beijo da palavrinha, original em língua portuguesa, do escritor moçambicano Mia 
Figura 2

Rodolfo o Carneiro, p. 11.

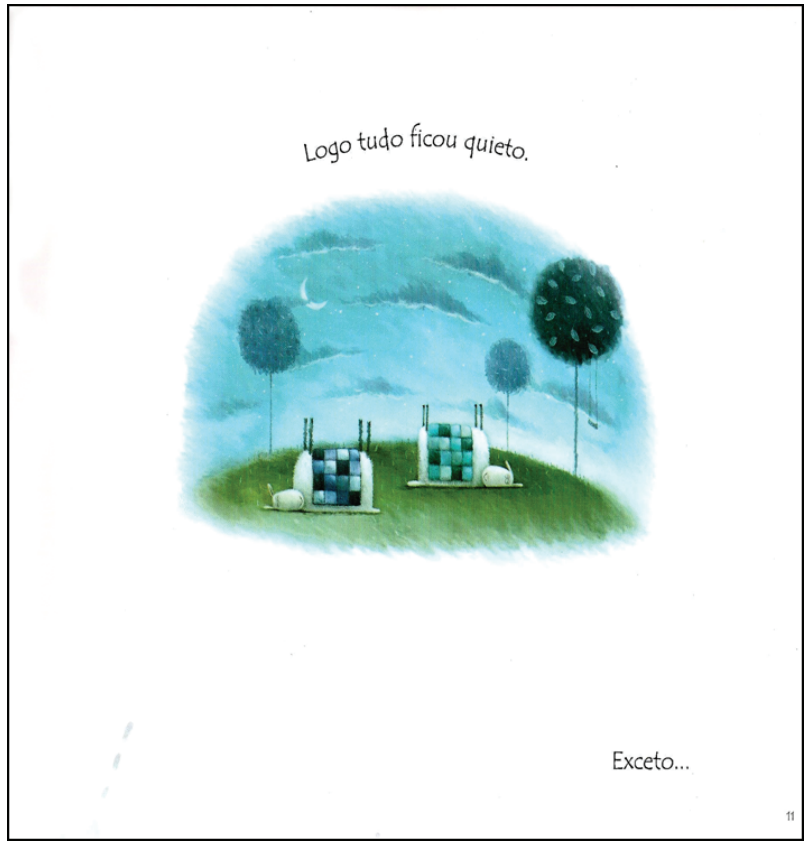

Fonte: Scotton (2006).

Couto, com ilustração do artista plástico seu conterrâneo Malangatana: é um livro que evidencia o encontro, no discurso literário, de formas de visualidade através da palavra escrita. Não é só o projeto gráfico que orienta as imagens e a escrita verbal para criar novas formas de leitura, mas a narrativa que ultrapassa o simples relato. Para salvar a menina que adoecera, seria preciso ir ao litoral, para que ela "renascesse tomando conta daquelas praias de areia e onda. E descobrisse outras praias dentro dela" (Figura 3). Aos poucos, o leitor, de forma metonímica, vai sendo levado por Zeca Zonzo, que era desprovido de juízo e que, por isso mesmo, conseguiu salvar a irmã: outras vias, outro olhar, outra compreensão. Impossibilitada de ir de corpo ao mar, a salvação da menina começa pela escrita:

"- Vou-lhe mostrar o mar, maninha." Todos pensaram que ele iria desenhar o oceano. Que iria azular o papel e no meio da cor iria pintar uns peixes. E o Sol em cima, como vela de bolo de aniversário. Mas não. Zonzo apenas rabiscou com letra gorda a palavra "mar". Apenas isso: a palavra inteira e por extenso. 


\section{Figura 3}

\section{0 beijo da palavrinha, página dupla.}

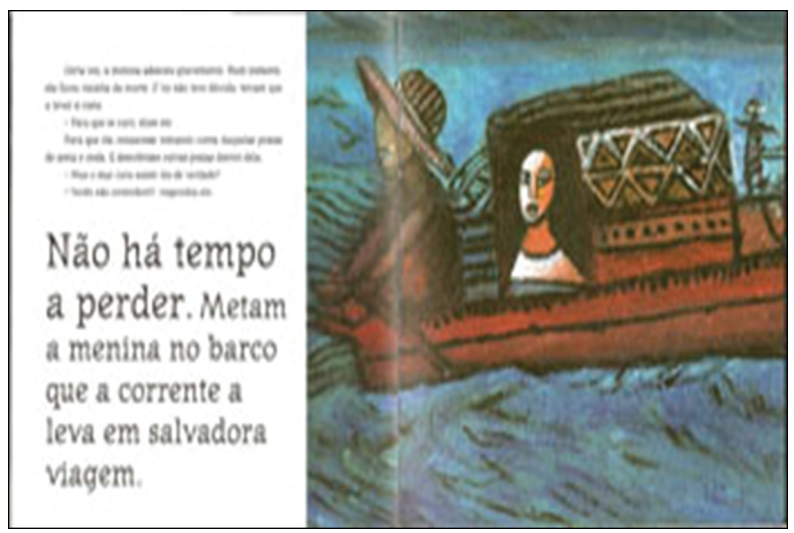

Fonte: Couto (2006).

A sua desrazão consegue guiar os dedos da maninha para a leitura de um mundo que ela desconhece e que vai construindo aos poucos pela relação tátil com o papel onde a palavra está escrita: "Zeca Zonzo levantou os dedos da irmã e soprou neles como se corrigisse algum defeito e os ensinasse a decifrar a lisa brancura do papel”. As letras $\mathbf{m}, \mathbf{a}, \mathbf{r}$ ganham a força de uma realidade ideogramática das ondas, da gaivota e da rocha que se distinguiam pelos dedos da menina (Figura 4): a letra " $\mathrm{m}$ é feita de vagas, líquidas linhas que sobem e descem". Já o a é "uma gaivota pousada nela própria", enquanto que os dedos da menina se magoam no "r duro, rugoso, com suas ásperas arestas”. Mais que uma metáfora, a existência das letras são uma realidade para a menina que se salva quando cria, pelo tato, o mar e suas ondas, a rocha que nele habita e as gaivotas. Essa experiência é um prolongamento físico do mundo, passar os dedos nas letras é passar as mãos nos objetos que a aproximarão da eternidade, como se o movimento esculpido de suas mãos trouxesse o mar da sua salvação (Figura 5).

Figurar e representar, nesse caso, dão poder à imagem arcaica. A relação arbitrária entre grafema/fonema é substituída pela sensibilidade tátil do desenho da letra, posto que refazer a forma gráfica com os dedos concretiza a existência das coisas e lhe dá significado. Debray (1993, p. 14), a propósito do seu estudo sobre a história das imagens no Ocidente, comenta a preocupação de um imperador chinês em pedir ao principal pintor da corte para apagar a cascata pintada em afresco na parede do palácio porque o ruído da água impedia-o de dormir. E acrescenta que, ainda na Renascença 


\section{Figura 4}

O beijo da palavrinha, página dupla.

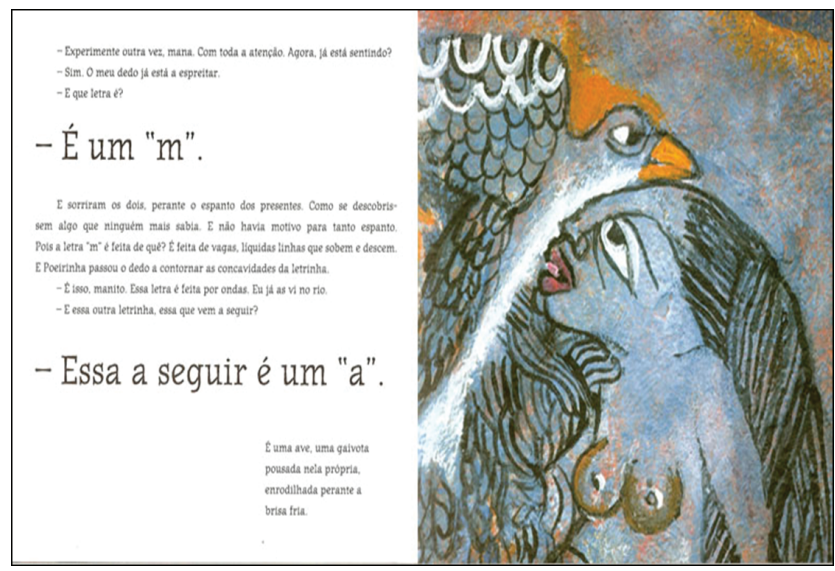

Figura 5

0 beijo da palavrinha, página dupla.

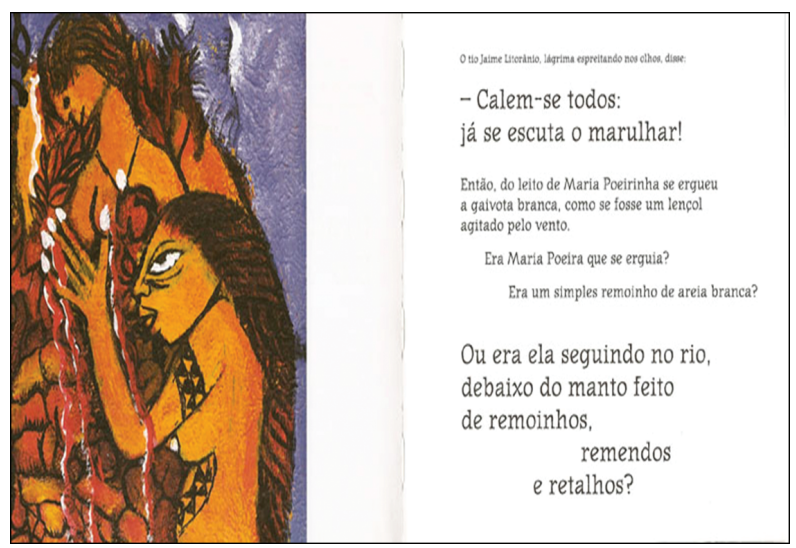

Fonte: Couto (2006).

florentina, Leon Alberti sugere que "[...] ver pinturas representando fontes, rios e cascatas faz muitíssimo bem aos febris. Se alguém, durante a noite, não consegue dormir, ponha-se a contemplar nascentes e o sono há de chegar”. A potência da imagem, portanto, é poder apresentar não um sucedâneo de algo mas esse algo transferido, como se sua alma estivesse ali presente.

Por outro lado, a presença do mar através dos dedos da menina aproxima-se do modo como Samain (1998) entende a visualidade originária (1998, p. 13): 
Tinha, primeiro, avistado o mar. Foi muito mais tarde que consegui nomeá-lo e dele falar e precisei de muitos outros anos de alfabetização para que, enfim, pudesse escrever seu tão pequeno nome... Dessa maneira, falar do fotográfico será, necessariamente, procurar situá-lo na perspectiva e no traçado de uma visualidade originária e constitutiva do ser humano, que teve de atravessar, ao longo de milênios, outros meios de comunicação que foram e são ainda a oralidade e a escrita, antes de poder constituir-se como fotografia. Não receio em dizer assim que o fotográfico representa nossa visualidade primeira que, quase submersa, durante séculos, nas águas da oralidade e da escrita, remontou, muito recentemente, à superfície, dando-nos a ver o mundo através de uma mediação técnica suplementar: o próprio dispositivo fotográfico e o signo visual singular que ele proporciona.

O que permitiu à protagonista Maria Poeirinha cumprir seu destino é esse caráter constitutivo do ser humano que, mesmo no caso dela, que não conhecera o mar, define um estar no mundo.

Esse modo de compreender a imagem dá sentido ao diálogo do texto com os quadros do artista plástico Malangatana para seu processo de ilustração, uma vez que ele vai buscar essa visualidade originária e expressar o fotográfico que há no artista por meio de uma plasticidade étnica, vigorosa como o texto e portadora de fendas de leitura pelas quais a desejada estética comparada da primeira década do século XX se realiza.

A menina que precisava da salvadora viagem em direção ao mar, de sentir e respirar a maresia para sobreviver, fez do passar os dedos a sua viagem, da escrita o seu mar e todos se calaram para escutar o marulhar: "Foi beijada pelo mar. E se afogou numa palavrinha". A imagem reconhecida do mar está presente como um estado do pensamento, como a potência do fotográfico que se concretiza na escrita do irmão Zonzo. As letras são o índice da presença do objeto. E o índice é a mais primitiva relação como o real, a marca do objeto e da sua existência. Fraca e quase cega, sua mão é a possibilidade tátil de conexão com o mundo, instituindo a dimensão do sensível como o lugar de expressão e conhecimento.

São dez telas que ilustram cenas da narrativa e a opção de apresentar todas elas ao final do livro permite admirar o trabalho do artista, mesmo que em pequeno formato, de uma forma inteira, autônoma, que libera as artes plásticas para comporem e proporem, ora com partes dos quadros, ora com a tela inteira, diálogos entre o plástico e o verbal. Seja brincando com frases, seja abrindo o branco para o infinito ou escrevendo sobre a tela, fica claro que são duas obras que se apresentam por inteiro para leitura. 
Do ponto de vista pragmático, a tarefa de ilustração em $O$ que o coração mandar, texto de Ayêska Paulafreitas e ilustração de Elvira Vigna, pode fornecer um trabalho exemplar. Tanto na concepção quanto na técnica, Vigna tem em mente a importância do leitor. Ele é seu norte e, por isso, todo o tempo o leitor está presente no seu trabalho. As ilustrações partem de fotos suas de casarios de Jequié, BA, que são redesenhadas com um trabalho de cor. O desenho é uma tomada de posse, não mimetiza a narrativa, pois se tratam de dois tipos de comunicação distintos e servem a finalidades diferentes. A propósito de situações escolares, Elvira Vigna ${ }^{3}$ afirma que o educador deve estar atento a esse fato, para melhor situar seus objetivos, sem perder de vista a importância da palavra. Como escritora que é, observa também que ler imagem não é necessariamente ler conteúdo da narrativa e que os professores têm se detido nesse aspecto da leitura da imagem. A artista apresenta três níveis de atividade do ilustrador: num primeiro nível, ele reproduz o que está escrito; num outro nível, o objeto reproduzido tem um olhar do ilustrador; e, num terceiro nível, mais profundo, o ilustrador cria um clima, não precisa retratar o objeto propriamente. Sua crença é a de que, se o trabalho do artista consegue estabelecer com o interlocutor um valor de afeto, ele estará realizando um trabalho literário valioso. E se as crianças se relacionam afetivamente com o objeto, tudo valeu a pena.

A história que Vigna ilustra é a de uma personagem que está voltando à cidadezinha de Jequié, BA; sua figura é retratada com um lápis preto em volta (Figura 6), destacando-se do cenário. Na verdade, ele ainda está entrando na cidade e, por isso, essa sua forma de participação na história. A artista não apresenta uma imagem acabada, tanto no formato quanto nos conteúdos semânticos. O que ela propõe é a falha, a imperfeição, pois só aí, no seu dizer, é que ela invocará a presença do leitor para construir sentidos possíveis. 'Tem que haver um 'entre'. A rua acaba, não sei onde, o que tem atrás, não sei, a figura não se completa, está solta no espaço, na capa a terra escorrega, está solta [...]” (Figura 7). A essa situação Bakhtin (2000, p. 43) chama excedente de visão e que permitirá construir seu conceito de exotopia, uma posição exterior que condiciona o excedente de visão.

Esse excedente constante da minha visão e de meu conhecimento a respeito do outro é condicionado pelo lugar que sou o único a ocupar no mundo: neste lugar, neste instante preciso, num conjunto de dadas circunstâncias - todos os outros se situam fora de mim. (BAKHTIN, 2000, p. 43). 
Figura 6

0 que o coração mandar, página dupla.

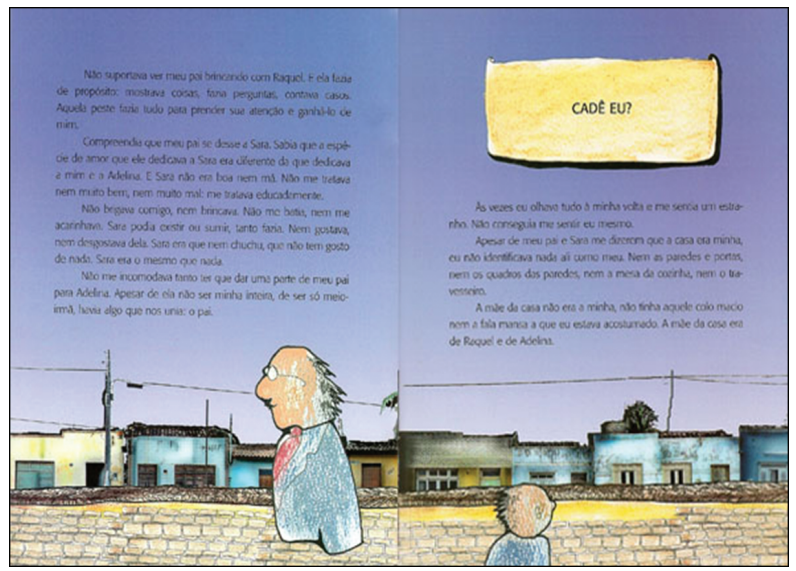

Fonte: Paulafreitas (2005).

Figura 7

0 que o coração mandar, página dupla.

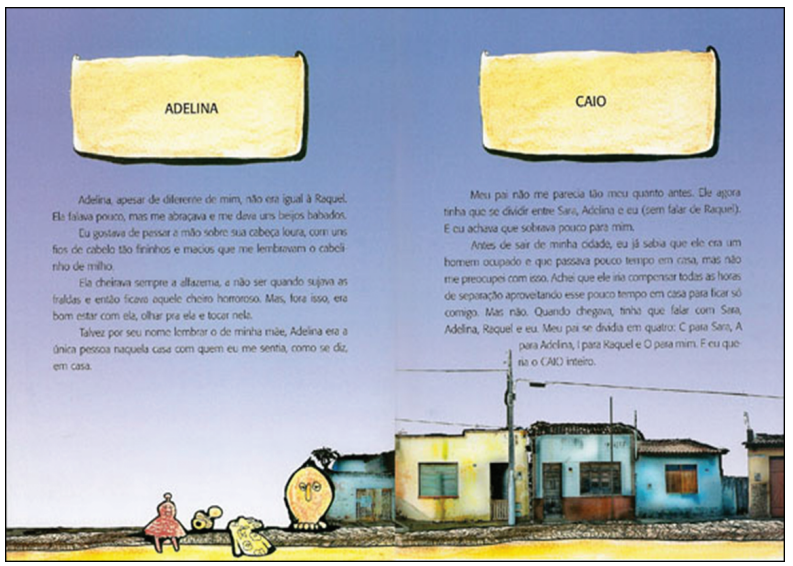

Fonte: Paulafreitas (2005).

Essa constante solicitação da presença do outro é o que Elvira Vigna deixa para o leitor e permite melhor compreender o trabalho de quem não concebe a ilustração como imagens fechadas. A convocação à atividade estética de acabamento de sua obra é o que propõe a ilustradora e o leitor terá espaço para ratificar o projeto bakhtiniano de produção de sentidos. 


\section{O DISCURSO E A VISUALIDADE NA PRODUC̣ÃO NARRATIVA}

São apresentadas, nesta seção, algumas abordagens sobre a relação entre o icônico e o verbal, evidenciando questões que podem contribuir com a problematização do livro de literatura infantil, mais especificamente, do livro ilustrado.

Característica das leis da comunicação verbal, a narrativa prevê um sistema fixo de signos e de sintaxe que garante um ordenamento linear e temporal próprio do sistema alfabético. Em contrapartida, uma escrita mais dinâmica e liberta de normas canônicas credita mobilidade de signos e de sintaxe e autoriza diferentes leituras, polissêmicas, umas até antagônicas a outras.

Por outro lado, as figuras nas telas de pintura evocam uma história que, por sua vez, está presente na nossa memória. Entre as figuras, a presença do vazio aproxima e compõe relações que criam enredos. É essa memória que é evocada pela tela que produz narrativa, que capta e devolve um modo particular da forma como a cultura se preserva.

Outra questão de interesse para a presente discussão refere-se à descrição pictural nos textos literários. Louvel (2006, p. 218) define iconotexto como "[...] presença de uma imagem visual convocada pelo texto e não somente a utilização de uma imagem visível para ilustração ou como ponto de partida criativo [...]", no intuito de organizar um modelo retórico de descrição pictural. Afasta qualquer função pedagógica que se aproprie dos procedimentos da descrição em geral e investe no que ela define como uma figura da figura, isto é, uma analogia entre artes, em que a imagem no texto - a que vai ser descrita - será tratada por um procedimento de translação, de passar de um lugar para outro, de uma linguagem para outra, de um código semiológico a outro. A pesquisadora (2006, p. 196) afirma:

O iconotexto [...] se coloca em situação de "duplo desligamento": na "translação pictural", diferentemente da tradução linguística (passagem de um significante a outro, de mesma natureza, linguístico), efetua-se a passagem de um significante (pictural) a um outro significante (linguístico) de natureza diferente. Nesta translação midiática, todas as metamorfoses, todas as manipulações que o escritor quiser impor à obra artística serão permitidas. 
Mesmo alinhada à tendência de Lessing, que classifica as artes do tempo e as artes do espaço, a pesquisadora procura o que há de espacial na linearidade da escrita literária através de recursos linguísticos de espacialização textual: a grafia de letras, os dêiticos, os encadeamentos de narrativas, entre outros, a diagramação da página, os brancos tipográficos são efeitos de enquadramento que sublinharão a passagem da narrativa à descrição pictural. Ao resultado do uso desses procedimentos ela chama de efeito de imagem. Recupera os estudos de Derrida sobre a pintura para entender o efeito da moldura que ele define como efeito parergon: “[...] nem dentro, nem fora da obra: a moldura efetua a passagem entre eles, aponta a obra como de-marcável [...]” (LOUVEL, 2006, p. 196).

É frequente, na história das relações entre essas artes irmãs, uma servir de modelo para a produção da outra, isto é, artistas pintam a partir de descrições literárias ou escritores apresentam sua leitura das obras de arte através de textos poéticos, seja em prosa ou poemas. Nesse caso, o que se faz ultrapassa a simples descrição de uma arte pela outra e afasta a ideia da ilustração como tradução do legível. Todavia, não se devem esquecer os múltiplos exemplos da História da Arte que apontam inúmeras obras de arte que tomam outra como parâmetro e que realizam comentários, referências, paródias, verdadeiros estudos a partir das interlocuções travadas.

Historiadores da arte mostram que a integração da narrativa na pintura ocidental tem intenso momento de elaboração de uma nova linguagem artística nas miniaturas das iluminuras, que se destinavam, em princípio, a uma elite intelectual: são o que eles chamam de "[...] campo de experimentação da pintura, laboratório de novos procedimentos [...]”. Sterligov (1996, p. 8) explica:

A elaboração de uma nova linguagem artística - aquisição do espaço, experimentação de massas, de volume, de movimento etc. - se efetuou para muitos nas oficinas dos iluminadores. As funções de ilustração incitaram os autores de miniaturas para a narração, o discurso, os detalhes do real, para uma tentativa de transformar em imagem não somente o espaço mas também a duração.

Isso justifica o empenho com que as imagens da Idade Média foram usadas para traduzir textos e orientar os analfabetos na leitura das escrituras cristãs com o peso do convencimento retórico. O interesse 
evidentemente pedagógico da substituição da narrativa composta por letras e palavras - alfabética - pela narrativa com figuras muda o modelo verbal por outro que também se organiza em torno do verbal. A preocupação com uma explicação literal do mundo faz as imagens desse período, principalmente dos séculos XI e XII, se submeterem à lógica do discurso. Do ponto de vista educativo, o uso das imagens de diferentes formatos e tipos foi largamente difundido, adquirindo colorido próprio de acordo com as épocas e ideologias.

O processo por que passaram as imagens, de intensa absorção de algumas qualidades discursivas, como a descrição, a narração e a argumentação retórica, se espalhou por diferentes modalidades expressivas e de variadas maneiras; o corte que se propõe para o século XIX quer enfatizar o movimento ao contrário, de as palavras se apropriarem, na visibilidade, do modelo da espacialidade: principalmente a litogravura, por um lado, e a poética de Mallarmé, por outro, devolveram, sob formas artísticas do plástico e do verbal, um modelo de visualidade letrada ou, dito de forma condensada, verbovisual ${ }^{4}$. Se as imagens serviam para, na sua origem, o homem se comunicar com os deuses; se, depois, o homem se serviu da imagem para tornar visível o invisível; se a imagem da sociedade ocidental absorve o logocentrismo e suas estruturas discursivas; e se, mais ainda, o sistema de escrita alfabético se apropria das imagens para seu uso no nível fonológico, em substituição às letras; então expõem-se diferentes dinâmicas de convivência sempre renovadas no âmbito das diversas formas de comunicação, das expressões plástica, gráfica, literária, contribuindo para o aprendizado e expressão da cultura.

Essas reflexões trazem um novo elemento para a elaboração de um quadro de referências na construção de um arcabouço conceitual. A discussão sobre a linguagem do desenho, além de elaborada por muitos críticos das artes plásticas, também o é, no caso brasileiro, por Andrade (1965), que transita entre diferentes artes, como a fotografia, a música, a literatura de ficção e a poesia, além da escrita de argumentação teórica: dissociando o desenho das artes plásticas e da escrita, cabe à mão do artista o estilo que definirá uma caligrafia, uma escritura, considerando, para isso, as pinturas primitivas que estariam mais próximas da natureza gráfica do desenho. Mas, para isso, Andrade recorreu à polarização constante na definição de artes do tempo e artes do espaço, proposta por Lessing. Embora não se 
apoie no suporte como critério distintivo, como faz Christin, ultrapassa a materialidade como conceito e considera o desenho um fato aberto. Se é certo que objetivamente ele é também um fenômeno material, ele o é apenas como uma palavra escrita (p. 72). Lembra ainda que o traço é uma convenção e que “[...] não existe no fenômeno da visão, nem deve existir na pintura verdadeira ou na escultura [...]”, pois, mesmo a possibilidade de delimitar o desenho.

Diferentemente da pintura, cuja validade estética está na ordem da composição, a sua argumentação compreende o desenho como uma definição: ao mesmo tempo uma transitoriedade e uma sabedoria (mesmo que não seja eterna). É, como diz ele, uma espécie de provérbio, pois exprime uma experiência vivida e transformada numa definição eminentemente intelectual; assemelha-se a uma frase feita, que se liberta das fragilidades sentimentais da frase espontânea e assume sua forma definitiva. Essa depuração lhe concede a natureza essencialmente poética do provérbio, pois condensa, define-o e o afasta "[...] da natureza descrevedora e contemporaneamente raciocinante da prosa $[\ldots .$. ” (p. 76).

Percebe-se desse modo que mesmo libertando o desenho da comparação com o prosaísmo - que absorve, longamente no tempo, sentimentos, pontos de vista, enfim, condicionantes que organizam a forma -, mantém-se sua delimitação, ainda que intelectualmente o traço não lhe aprisione o sentido, na esteira da linearidade da escrita alfabética. Supera essa dualidade, todavia, pela caligrafia; dito de outra forma, pelo estilo.

Todavia, a retomada da ideia de entre, proposta por Christin, recupera o fundo e coloca toda a história das relações entre artes plásticas e literatura num patamar que revigora a discussão sobre a natureza da escrita, uma vez que nem palavra nem figura são isoladamente. Desde o fim do século XIX (1897), com Un coup de dés n'abolira jamais le hasard, Mallarmé redesenha a poesia do século seguinte e toda a literatura, integrando os elementos visuais perdidos. Sempre a literatura avançando na revisão de suas premissas e propondo, neste caso, uma retomada da imagem pela escrita alfabética. $\mathrm{O}$ espaçamento da leitura, como ênfase da imagem poética, o caráter gráfico das letras e figuras desenhadas na página criam uma aproximação, segundo Mallarmé, com a partitura musical, como o tempo fraco ou forte, a pausa, vista não como ausência de som mas como presença de ritmo e de leitura, são aproximações com uma visualidade ainda impensada ou esquecida pela 
história da escrita alfabética. Nesse aspecto, aproxima-se da oralidade que reconhece o ritmo, a cadência, a toada. A leitura simultânea do poema em página dupla oferece uma nova forma de ler similar à da imagem e, nesse caso, distante da palavra oral. Por isso, a linguagem se aproxima da escrita e se afasta da palavra viva, como mostra da existência material do verbo.

As experiências nas artes plásticas, na literatura e, fundamentalmente, no design gráfico ao longo do século XX reaproximam a escrita e a pintura e constroem olhares acostumados com as multiformas gráficas, que tornam automáticos e, por vezes, vulgares a coexistência de palavras e imagens como forma de entendimento dos usos da espacialidade e da visualidade. Por isso, Christin (1995) afirma, nas primeiras palavras de apresentação de seu livro, que "[...] a escrita deve ser compreendida no seu sentido restrito de veículo gráfico de uma palavra [...]”, o gráfico tomado como veículo de visibilidade, pois a escrita permite que a palavra se torne visível, assim como o fundo dá a ver a imagem.

Essa discussão põe em evidência o grafismo atual que vem sendo aproveitado na área da educação, seja como aplicação prática, seja como arte, não só na ilustração de textos verbais como também tomado como texto visual, o que possibilita aproximar o design gráfico de sua função utilitária e expressiva ao mesmo tempo. Portanto, resta redefinir que aspectos distinguiriam o grafismo como uma área de atuação específica na educação. Essa mistura de funções, ou melhor, essa desformatação de funções ajuda a reinventar formas de relação e formas de apresentação, o que pode aproximar a poesia do design, as artes da literatura. A proposta de uma interrogação visual seria bem acatada nos ambientes nos quais caberia interpretar as relações existentes entre seus traços e, eventualmente, seu sistema.

\section{OS EIXOS: PARADOXO E PARALELO}

Arbex (2006) oferece, em seu artigo Poéticas do visível: uma breve introdução ${ }^{5}$, uma revisão de propostas teóricas sobre literatura e artes plásticas e os níveis de relação entre o icônico e o verbal a partir da leitura de dois números da revista Textuel. A autora sinaliza dois grandes eixos de análise: os estudos que se baseiam no conceito de paradoxo e os voltados para o conceito de paralelo. 


\section{O PARADOXO}

O paradoxo se situa no movimento de aproximação e afastamento em que se encontram essas expressões artísticas. Essa permeabilidade de fronteiras entre os mundos do dizer e do ver, relação dinâmica entre esses polos, recusa as aproximações arbitrárias mas também os distanciamentos apressados e privilegia a noção de limite, de fronteira, o que está em jogo no entre a escrita e a imagem. Além dessas, também são características: diversidade de práticas e métodos de análise; necessidade de abordagens múltiplas e dinâmicas; pluralidade de enfoques empregados no tratamento do objeto de estudo, devido à heterogeneidade das obras em que o legível e o visível se reúnem. Olhar para essa tensão como um paradoxo é a opção de quem deseja enfatizar o caráter que deve predominar entre os polos. Os movimentos artísticos da modernidade operam uma conexão ou uma travessia entre os domínios literário e plástico, cada um com uma lógica semiótica, isto é, cada qual com seu código específico, seja verbal ou icônico, mostrando as diferenças entre esses regimes; algumas tendências preferem não priorizar um ou outro, mas manter o visível e o legível em tensão.

Essa é uma questão difícil de ser assimilada, por exemplo, pelo conceito bakhtiniano de signo neutro (2004, p. 36-37) que, de alguma forma, permite e facilita a entrada da linguagem verbal por entre as imagens, ajuda a compreendê-las e torna inteligíveis os seus conteúdos; todavia, não há nesse conceito, coerentemente, aliás, nenhuma referência ao espaço entre as imagens.

Acredito estar aí uma grande questão para a escola, uma vez que a tendência teórica de não polarizar posições deveria ter ressonância no modo de operar a realidade escolar, ampliando (e não reduzindo) a riqueza dos diferentes contatos produzidos por essa dinâmica. Acostumado à estabilização, à conformidade e à ordenação, o espaço escolar tende a falsear a tensão, não explicitando a presença, por vezes dominante, da linguagem visual nos processos de aprendizagem.

Arbex (2006) apresenta outro conceito importante de que autores vêm se apropriando para dar corpo ao conjunto teórico da perspectiva do paradoxo: é o de corte semiótico, a partir do qual os autores pensam as relações sob o signo da plasticidade. Para isso, se aproveitam das pesquisas de Pierce que, propondo uma triádica, amplia a relação binária saussureana que 
supõe uma lógica e permite realizar contatos que não sejam obrigatoriamente estáveis, mas transitórios e múltiplos. Muitos teóricos têm proposto uma revisão do conceito de mimese, além de estudo da materialidade da escrita e articulação de diferentes modalidades tipo-estilísticas. Parece que, com isso, propõe-se, ao fim e ao cabo, uma forma original de pensar e abordar o tema: aceitando uma diferença irredutível, surge a possibilidade de um novo gênero entre a pintura e a literatura, que a atividade estética tenta descobrir e atravessar. Consequentemente, a sequência de incômodos recai sobre o modo de organização das disciplinas que tornam suas margens mais fluidas: de um lado, a história da arte e a reflexão estética e, de outro, a história e a teoria literárias. Hoje, observam-se diálogos profícuos nas suas fronteiras, numa evidente necessidade de interdisciplinaridade como, por exemplo, em várias produções de literatura infantil que explicitam de maneira contundente a imbricação das funções de autoria, nela considerando tanto o autor do texto verbal quanto o ilustrador. Pode-se acrescentar a esse momento de tensão, contudo producente, entre essas duas áreas, outras tantas que fortalecem um intercâmbio, como a História Cultural e a Antropologia, explicitando, para a área da Educação, a emergência de abertura de novos campos para a prática educativa.

As diferentes investigações sobre os elos entre as imagens e o texto verbal têm provocado múltiplas propostas de classificação e de critérios operatórios, mas vale destacar que as frequentes interrogações sobre a imagem que gera o texto, ou a imagem no texto, ou de um texto que evoca uma imagem, enfim, constituem questões que variam de acordo com a delimitação do campo de estudos, privilegiando um certo enfoque. No momento, é relevante destacar uma abordagem sobre a anterioridade da imagem para gerar um texto de ficção, para mostrar uma base conceitual de alguns procedimentos escolarizados da aprendizagem da escrita em relação à descrição. São as imagens colocadas em palavras, a imagem no texto, que comportam a noção de descrição pictural. No ponto oposto, pensa-se a imagem com uma autonomia suficiente para que não dependa mais de um texto fonte. Eis uma questão a se discutir nos livros de literatura infantil, e talvez nos livros de alfabetização, já que muitas vezes a imagem não depende de texto, optando por um procedimento plástico, e, outras vezes, ela se define por um procedimento linguageiro. 
A base do percurso pelo qual todos os estudiosos adeptos do paradoxo optam está, antes de tudo, em quem fará o percurso. Importa dizer que os pesquisadores da história da arte, ou os adeptos da semiótica, ou mesmo os que querem ressaltar a autonomia da imagem em relação ao texto conferem valor à radical heterogeneidade da imagem para instaurar uma discussão que contraponha os poderes da escritura. Essa é uma questão fundamental para quem pensa a formação de professores de linguagem/ literatura da Educação Infantil e do Ensino Fundamental, uma vez que as crianças e jovens conjugam simultaneamente e com bastante naturalidade, no instante da compreensão, diferentes linguagens.

\section{O PARALELO}

Outra perspectiva do estudo é aquela a partir da noção de paralelo entre literatura e pintura. Arbex (2006, p. 38-40) situa o trabalho de Nella Arambasin como enfoque comparativista, uma vez que legitima uma proposta, pensada em 1947, de a literatura abrir-se "a uma estética comparada", para apresentar interdisciplinaridade em textos e escritas, decorrentes de uma reflexão própria às diferentes expressões artísticas. Sua origem remonta à Antiguidade com o ut pictura poesis, fundada sobre o paralelo baseado no princípio mimético, “[...] que não apenas rege todas as artes, mas conduz também a aproximá-las até o amálgama [...]”. Essa perpectiva horaciana vingou até o século XVIII, quando Lessing, historiador da arte, construiu um arcabouço teórico que se manteve até o século XIX. Dizia que era preciso mantê-las distantes e redefini-las, as artes e a poesia, dentro de seus limites, apresentando, consequentemente, a clássica depuração entre artes do espaço e artes do tempo. Por sua vez, o século XIX é portador de uma experimentação estético-literária que permite escrever sobre pintura e elaborar uma reflexão sobre a prática literária. Ora, essa presença constante da arte como temática de artigos, ensaios, textos de ficção propicia um olhar que amalgama os lugares dessas experiências estéticas, criando certas dificuldades para a modernidade que afirma a autonomia das artes, essa noção tão cara ao processo de assentamento do sujeito. Mesmo assim, o princípio do paralelo é mantido, como afirmação do distanciamento entre imagem e texto.

Vale a pena pensar o que essas relações ou esses rompimentos e fraturas entre essas artes podem significar para o estudo em questão. 
Não é o caso de optar obrigatoriamente por uma ou outra noção, mas dizer da impossibilidade de se manter distante da discusssão e, mais ainda, da necessidade de atentar para os impasses por que passa a convivência entre esses dois domínios. Chamar a pintura de linguagem é submetê-la a padrões de conformidade verbal; chamar o texto de imagem (como querem os estudiosos do design gráfico) é submeter o texto à plasticidade da figura. Mais do que o que são essas linguagens, vale aproveitar o como se dão essas relações para que se possa depreender, em materiais que circulam na escola, as diferentes formas de aproximação entre imagem e texto. Talvez fosse mais proveitoso recuperar o tanto de linguagem e de imagem que há nos dois domínios. Por isso, Arambasin continua apontando, no século XX, alguns movimentos de substituição e deslocamento dos antigos paralelos, redundando em propostas de gêneros como, por exemplo, os híbridos.

Tal como a tensão que permanece no gênero entre a pintura e a literatura, na perspectiva do paradoxo, o ponto de vista do paralelo entre as artes e a literatura recria essas novas possibilidades de gêneros. Vale lembrar que o hibridismo em Bakhtin (1998, p. 156-163) aponta para uma resultante de misturas que ampliam a dialogicidade inerente ao discurso. São pequenas alterações e interferências no modo de estruturar o conceito que fazem essa situação de enfrentamento tomar pequenas variações fundamentais que ajudarão a recolocar as relações entre imagem e texto nos ambientes escolares.

A afirmação de Guimarães (1997, p. 216) sobre literatura e cinema: "[...] a escritura promove a migração de imagens - do real para o espaço da textualidade [...]", pode ser transposta para o plano da palavra e imagem nos processos de leitura literária. Esse deslocamento mostra que os estudos acerca dessa relação desejam superar a dicotomia ver versus ler, adicionando ao ver estatuto de ler alguma coisa, e ao ler, as condições de poder ver alguma coisa. O que os une é o dizer e isso solicita uma discursividade que recupera a presença dos interlocutores e seus atos de fala.

\section{REFLEXÕES FINAIS}

Este texto pretendeu oferecer uma rede conceitual que amparasse uma análise crítica das relações entre textos verbais e visuais em livros de literatura infantil, especialmente os livros ilustrados. Para isso, considerou a literatura e as artes visuais e gráficas como parâmetros a partir dos quais tomaram corpo as experiências estéticas dessas áreas. 
Consequentemente destacou-se um arco de possibilidades para a construção de reiterações, especificidades, alternâncias no uso dessas linguagens. As relações entre o icônico e o verbal são múltiplas e perpassam, no plano artístico, uma infinidade de possibilidades de interação: pelo texto verbal evocando a imagem; ou, ao contrário, a presença da imagem como motivadora para a escrita; pela riqueza da exploração polissintática do espaço, através do conceito de superfície, que recupera o fundo como integrante da constituição da imagem, sua figuração; pela presença da imagem no texto ou do texto na imagem, o iconotexto, fundamental para se pensar contemporaneamente os diferentes usos de imagens e palavras que são propostos nos livros de literatura infantil; pelo traço como gesto criador de enunciação do homem e como denúncia da dupla origem da escrita, gráfica e verbal; pelos conceitos de paradoxo e paralelo que possibilitam compreender a rica teia de relações entre imagem e texto verbal; pela hibridização de linguagens que, ao final, explicita a necessidade de se rediscutir o conceito de autoria: qual a importância e o lugar do ilustrador como coautor do livro de literatura infantil?; pela exotopia, que denuncia a presença do outro como excedente de visão e o inclui como produtor de sentidos.

Pensar essas questões para a formação do mediador que estará em contato com leitores mirins e jovens torna-se fundamental e o professor que tem interesse em construir uma competência estética tem mais facilidades no trato das questões propostas nos livros de literatura infantil, nas revistas de arte, nos livros didáticos, em qualquer suporte em que a sua sensibilidade e seu conhecimento sejam solicitados.

Seja em texto literário - romance, conto, poesia, crônica -, seja em artes visuais e gráficas - pintura, escultura, fotografia, desenho etc. -, seja na relação dos dois, é com o intuito de aprender, entendido como um tipo de habilidade que deve ser cultivada nas práticas cotidianas e experimentais, que o professor - na sala de aula com o aluno - situa sua ação de saber. Não só desejo para aprender, mas também disposição intelectual para apropriação de novas formas de organização do conhecimento refletem a afirmação de Olson (1997, p. 246-247): tanto palavras quanto imagens se tornam recursos conceituais e técnicos que permitem a aprendizagem de distintas propriedades do mundo e das formas que tornam essas propriedades visíveis, pois não bastam "[...] um olho sincero e uma mão fiel para ver tudo o que há; é preciso, além disso, uma mente educada”. 
A interrogação que persiste e que, pela impossibilidade de resposta nesse momento histórico, se coloca como um horizonte para futuros estudos é se a escola, ao constituir uma teoria da imagem para viabilizar sua prática de sala de aula, poderá repetir os processos de conservação e fixidez que constituíram a aprendizagem da escrita, esvaziando a flexibilidade de tipos, de frequência, de modos de utilização com que elas ocorrem, levando-as a perder sua polissemia, seu traço criador. Reafirma-se, todavia, que as implicações acerca da aprendizagem da escrita devem reconhecer o surgimento de uma nova mentalidade que amplia a mentalidade letrada e dela se apropria para novas relações apoiadas na visualidade e na oralidade, para integrar-se ao fórum de discussões contemporâneas que lhe são propostas pelos estudos culturais. Dessa forma, a escola escolariza, mas os sistemas de aprendizagem devem permitir sua comunhão com a estética sem que isso restrinja o caráter criador sem o qual o homem torna-se apenas reprodutor. 


\section{REFERÊNCIAS}

ANDRADE, M. Do Desenho. In: ANDRADE, M. Aspectos das Artes Plásticas no Brasil. São Paulo: Martins, 1965. p. 69-77.

ARBEX, M. Poéticas do visível: uma breve introdução. In: ARBEX, M. (Org.). Poéticas do visivel: ensaios sobre a escrita e a imagem. Belo Horizonte: Programa de Pós-Graduação em Letras, Faculdade de Letras, UFMG, 2006. p. 17-62

BAKHTIN, M. O Discurso na poesia e o discurso no romance. In: BAKHTIN, M. Questões de literatura e estética: a teoria do romance. São Paulo: Ed. Unesp, 1998. 439 p.

BAKHTIN, M. Estética da criação verbal. Tradução a partir do francês de Maria Ermantina Galvão G. Pereira. São Paulo: Martins Fontes, 2000.

BELMIRO, C. A. Um estudo sobre relações entre imagens e textos verbais em cartilhas de alfabetização e livros de literatura infantil. 2008. Tese (Doutorado)-Universidade Federal Fluminense, Faculdade de Educação, Niterói, 2008.

CHRISTIN, A.-M. L'Image écrite. Paris: Flammarion, 1995.

DEBRAY, R. Vida e morte da imagem: uma história do olhar no Ocidente. Tradução de Guilherme Teixeira. Petrópolis: Vozes, 1993.

GUIMARÃES, C. Imagens da memória: entre o legível e o visível. Belo Horizonte: Pós-Graduação em Letras, Ed. UFMG, 1997.

LOUVEL, L. A descrição "pictural": por uma poética do iconotexto. In: ARBEX, M. (Org.). Poéticas do visível: ensaios sobre a escrita e a imagem. Belo Horizonte: Programa de Pós-Graduação em Letras, Faculdade de Letras, UFMG, 2006. p. 191-220.

MIGNOLO, W. D. Literacy and the colonization of Memory: writing histories of people without history. In: KELLER-COHEN, D. Literacy: Interdisciplinary Conversations. New Jersey: Hampton Press, Inc., 1994. p. 91-113.

OLSON, D. O Mundo no Papel: as implicações conceituais e cognitivas da leitura e da escrita. Tradução de Sérgio Bath. São Paulo: Ática, 1997. (Coleção Múltiplas Escritas).

SAMAIN, E. O Fotográfico. São Paulo: Hucitec, CNPq, 1998.

STERLIGOV, A. Introdução. In: VORONA, T.; STERLIGOV, A. Manuscrits enluminés occindentaux. VIII ${ }^{\circ}$-XVI ${ }^{o}$ siècles. Tradution de Mirreille Faure. Saint-Pétersbourg: Éditions Parkstone: bournemouth, Éditions D’Art Aurora, 1996.

\section{Livros analisados}

COUTO, M. O Beijo da palavrinha. Ilustrações de Malangatana. Rio de Janeiro: Língua Geral Editores, 2006.

PAULAFREITAS, A. O que o coração mandar. Ilustrações de Elvira Vigna. Belo Horizonte: Dimensão, 2005.

SCOTTON, R. Rodolfo, o carneiro. Tradução de Ana Maria Bergin. Rio de Janeiro: Rocco, 2006. 


\section{NOTAS}

${ }^{1}$ Este trabalho faz parte de uma pesquisa de doutorado concluída sobre as múltiplas possibilidades de interação entre imagens e textos verbais em materiais que circulam na escola, a saber, cartilha de alfabetização e livros ilustrados de literatura infantil. Texto parcialmente apresentado na $34^{\mathrm{a}}$ Reunião Anual da Associação Nacional de Pós-Graduação e Pesquisa-ANPEd.

${ }^{2}$ As traduções são de responsabilidade da autora deste artigo.

${ }^{3}$ Entrevista da ilustradora concedida à pesquisadora.

${ }^{4}$ A proposta de retomar obras do século XIX não significa esquecer as origens dessas relações intersemióticas que datam da época Clássica. Usa-se o termo ecfrase para definir, a partir de trabalhos poéticos, o modo de coexistência entre dois sistemas de significação, suas mútuas influências e apropriações e suas transposições intersemióticas. Ecfrase vem do grego EKPHRASIS e significa, por sua origem, descrição, ou ek: fora + phrasis: frase, fora da frase. Ver a esse respeito trabalhos na área dos estudos literários como, por exemplo, Cordeiro (2003), Santos (2006), entre outros.

5 Arbex (2006, p. 17-62), artigo que resume parte de seu relatório de pós-doutorado.

Recebido: 24/06/2012

Aprovado: 03/12/2012

Contato:

Universidade Federal de Minas Gerais

Faculdade de Educação

Av. Antônio Carlos, 6627, Pampulha

CEP $31270-901$

Belo Horizonte, MG

Brasil 